\title{
Obtenção de compósito com matriz de acetato de celulose e partículas de prata para aplicações antimicrobianas
}

\section{Cellulose acetate and silver particles composite synthesis to antimicrobial applications}

\author{
Oscar Giordani Paniz ${ }^{1}$, Letícia Klein Scheik ${ }^{2}$, Gabriela Escobar Hochmuller da Silva ${ }^{3}$, \\ Margarete Regina Freitas Gonçalves ${ }^{1}$, Amanda Dantas de Oliveira ${ }^{1}$, \\ Edcleide Maria Araújo ${ }^{4}$, Neftalí Lenin Villarreal Carreño ${ }^{1}$
}

\footnotetext{
${ }^{1}$ Programa de Pós-Graduação em Ciência e Engenharia de Materiais, PPGCEM , Universidade Federal de Pelotas, CEP: 96010-610, Pelotas, Rio Grande do Sul, Brasil.

${ }^{2}$ Departamento de Ciência e Tecnologia Agroindustrial, DCTA, PPGCTA, Universidade Federal de Pelotas, CEP: 96900-010, Capão do Leão, Rio Grande do Sul, Brasil.

${ }^{3}$ Centro de Desenvolvimento Tecnológico - CDTec., Engenharia de Materiais, Universidade Federal de Pelotas, CEP: 96010-610, Pelotas, Rio Grande do Sul, Brasil.

${ }^{4}$ Unidade Acadêmica de Engenharia de Materiais, UAEMa, Universidade Federal de Campina Grande, CEP: 10034 58109-970, Campina Grande, Paraíba, Brasil.

e-mail: oscar.paniz@hotmail.com, leticiascheik@hotmail.com, gabrielahochmuller@gmail.com, margare-

terfg@gmail.com, amandaoliveira82@gmail.com, edcleide.araujo@ufcg.edu.br, neftali@ufpel.edu.br
}

\section{RESUMO}

O presente trabalho teve como objetivo empregar resíduos agroindustriais, especificamente fibras celulósicas extraídas de talos de casca de banana, para a obtenção de acetato de celulose. Tal produto por sua vez, foi utilizado como matriz em um compósito antimicrobiano para uso em embalagens de alimentos, constituído de acetato de celulose e partículas de prata. As referidas partículas foram produzidas por meio de síntese hidrotérmica assistida por micro-ondas a partir da redução do nitrato de prata, utilizando o citrato trisódico. As partículas de prata apresentaram um diâmetro médio de 433,6 nm. O compósito obtido foi caracterizado por microscopia eletrônica de varredura (MEV), testes de resistência à tração, análise termogravimétrica e espectroscopia no infravermelho por transformada de Fourrier (FTIR) e no UV-visível. Os resultados mostraram uma tensão de ruptura de aproximadamente $43 \mathrm{MPa}, 25 \%$ maior que a apresentada por polímeros comerciais sem a adição de cargas. Além disto, obteve-se propriedades bactericidas com relação as bactérias Staphylococcus aureus e Escherichia coli, quando em contato direto com o filme formado pelo compósito.

Palavras-chave: Fibras lignocelulósicas, celulose, compósito, atividade antimicrobiana, partículas de prata.

\begin{abstract}
The present work had the objective to use agroindustrial residues, specifically cellulosic fibers from banana peel stalks, to obtain cellulose acetate. This product, in turn, was used as a matrix in an antimicrobial composite for food packaging, consisting of cellulose acetate and silver particles. The silver particles were produced by microwave-assisted hydrothermal synthesis from the reduction of silver nitrate using trisodium cit-rate. The obtained particles had a mean diameter of $433.6 \mathrm{~nm}$. The composite was characterized by scanning electron microscopy (SEM), tensile strength test, thermogravimetric analysis, Fourier trans-form infrared (FTIR) spectroscopy and UV-visible spectroscopy. The results showed a fracture strain $25 \%$ greater than the commercial polymers without the addition of fillers, achieving about $43 \mathrm{MPa}$. In addition, bactericidal properties were obtained in relation to the bacteria Staphylococcus aureus and Escherichia coli when in direct contact with the composite film formed.
\end{abstract}

Keywords: Lignocellulosic fiber, cellulose, composite, antimicrobian activity, silver.

\section{INTRODUÇÃO}

O uso de polímeros em embalagens aumentou extraordinariamente nas últimas décadas devido as vantagens 
que estes oferecem em relação aos demais materiais, tais como: resistência à tração, flexibilidade e rigidez; barreira a umidade e a gases; resistência a ataques de componentes dos alimentos.

Além disso, os polímeros representam uma importante parcela da economia global, com mercado anual próximo à 100 milhões de toneladas, sendo que cerca de $42 \%$ dessas correspondem a embalagens [1]. Contudo, o acúmulo de plásticos no meio ambiente tornou-se um problema mundial, junto com o esgotamento de recursos naturais. Tal situação tem feito com que a comunidade científica explore alternativas aos polímeros baseados em petróleo [2]. Nesse aspecto a celulose merece destaque, visto que é o material natural mais abundante do planeta. Ela é utilizada como matéria-prima industrial para a produção de papel, biocombustíveis, biomateriais, compósitos e também para a produção de fibras sintéticas usadas como componentes em revestimentos, filmes óticos, alimentos, fármacos, cosméticos, aditivos e materiais de construção [3].

$\mathrm{O}$ acetato de celulose, um biopolímero obtido a partir da celulose, possui um conjunto de propriedades que fazem dele uma importante matéria-prima nas indústrias de fibras têxtis, tintas, plásticos, filtros e embalagens. Dessas destacamos a transparência, as propriedades mecânicas, a resistência ao calor, a baixa absorção de água e a facilidade na biodegradação [4]. Ademais, o acetato de celulose pode ser produzido a partir da biomassa de resíduos de algodão, de papéis reciclados, de madeira e também de resíduos agroindustriais, porém muitas possíveis fontes permanecem sem utilização [4]. Nesse aspecto o presente trabalho busca se diferenciar, uma vez que utiliza como matéria-prima para a produção do compósito acetato de celulose obtido a partir de talos de casca de banana.

No tocante a questão das embalagens, apesar da problemática ambiental, elas possuem um papel fundamental em nosso cotidiano. São parte integrante da produção de alimentos e responsáveis por protege-los de fatores ambientais como oxigênio, luz, vapores de água e micro-organismos [5], agindo como uma barreira física contra a ação de possíveis agentes contaminantes. Destacamos dentre esses o Staphylococcus aureus e Escherichia coli, bactérias causadoras de Doenças Transmitidas por Alimentos (DTA), que não causam nenhuma alteração visível nos alimentos, mas se presentes em determinadas concentrações podem causar danos à saúde do consumidor [6]

Staphylococcus aureus é uma bactéria formadora de toxina que pode acarretar uma intoxicação estafilocócica em quem ingerir o alimento com a toxina pré-formada, podendo conduzir o indivíduo à morte [7]. Portanto, a presença de um agente antimicrobiano na embalagem que protege o alimento seria não somente uma barreira física, mas também uma barreira química contra a ação de agentes biológicos indesejáveis.

As embalagens ativas agregam propriedades distintas aos invólucros convencionais e com isso aumentam o tempo de prateleira e a segurança dos alimentos, abandonado a estigma de simples recipientes de armazenamento [8]. Para conferir tais propriedades, diferentes partículas e nanopartículas são utilizadas em matrizes poliméricas como, por exemplo: substratos minerais contendo nanopartículas de prata e cobre em nanofibras de acetato de celulose atribuindo à essas atividade antifúngica [9]; Fibras de acetato de celulose e nanocelulose contendo íons e nanopartículas de prata obtidas por diferentes rotas demonstraram elevada atividade antibacteriana contra Escherichia coli e Staphylococcus aureus [10-12]; Compósitos de acetato de celulose e argila montmorilonita modificada com íons metálicos $\left(\mathrm{Cu}^{2+}\right)$ apresentaram $98 \%$ de redução contra Escherichia coli [8]; Recobrimento de substratos celulósicos flexíveis com nanopartículas de óxido de zinco promovendo ação hidrofóbica e antibacteriana [13].

A utilização de celulose e seus derivados em produtos antimicrobianos não se trata de uma novidade [14]. Além disso, a prata tem sido utilizada há séculos na prevenção e tratamento de enfermidades por conta de suas propriedades distintas [11,14]. Contudo, a prata e seus íons apresentam eficácia comprovada contra mais de 600 bactérias, apresentando um menor índice de toxicidade para as células humanas. Tais fatos justificam a sua ampla utilização tanto em trabalhos posteriores, como no presente estudo. Da mesma forma, existem diversos trabalhos que fazem uso do acetato de celulose como matriz em compósitos com prata [9$11,15]$, porém nenhum desses utiliza como matéria-prima os resíduos da banana.

Focado na busca de alternativas para a problemática da degradação do meio ambiente, o presente trabalho pesquisou a obtenção de um material polimérico natural (acetato de celulose), produzido a partir de resíduos agroindustriais, especificamente talos de casca de banana, ao qual foi adicionado partículas de prata, um reconhecido agente antibacteriano, visando a produção de um compósito bactericida passível de biodegradação, para ser utilizado em embalagens ativas. 


\section{MATERIAIS E MÉTODOS}

Para a obtenção do acetato de celulose utilizou-se como matéria-prima fibras lignocelulósicas extraídas de talos da casca de banana além de diversos reagentes químicos tais como ácido acético glacial, ácido clorídrico, ácido sulfúrico, anidrido acético, citrato de sódio, nitrato de prata, formaldeído, água destilada, clorofórmio, etanol, hidróxido de potássio e hidróxido de sódio, todos eles de grau analítico.

As fibras lignocelulósicas, obtidas a partir de uma adaptação da metodologia descrita por Beltran [16] e Paniz [17], foram submetidas a uma combinação de tratamentos álcali e de branqueamento para a eliminação dos compostos de baixo peso molecular, pectinas, ceras e lignina, obtendo-se ao final uma polpa celulósica [18]. Por fim, a polpa foi congelada e seca utilizando um liofilizador da marca Liotop, modelo L101.

Para a produção das partículas de prata fez-se uma adaptação na metodologia descrita por YIN et al. [19]. Para isso, $50 \mathrm{ml}$ da solução de citrato trisódico (1,5 mol/l) foi colocada em um frasco reacional sob agitação constante, sendo em seguida adicionado por gotejamento $50 \mathrm{ml}$ da solução de nitrato de prata $(0,1$ $\mathrm{mol} / \mathrm{l})$. Quando a mistura estava homogênea, adicionou-se também por gotejamento 10,91 $\mathrm{ml}$ de Formaldeído a 37\%. A solução foi então colocada em um reator de politetrafluoretileno, o qual foi inserido em um forno de micro-ondas adaptado para sínteses hidrotérmicas, da marca Eletrolux com potência de 1500 watts. Utilizou-se a temperatura de $160^{\circ} \mathrm{C}$ por 2 minutos e pressão de 4,50 $\pm 0,5 \mathrm{~Pa}$ para promover a reação. $\mathrm{O}$ material obtido foi lavado e centrifugado diversas vezes para a remoção do formaldeído, sendo posteriormente seco em estufa por $24 \mathrm{hs}$ à $60^{\circ} \mathrm{C} \pm 10^{\circ} \mathrm{C}$. As partículas de prata obtidas tiveram sua morfologia avaliada por meio de microscopia eletrônica de varredura, utilizando um microscópio da marca Jeol - modelo JS-M6610VL, com intensidade de feixe de 15 quilovolts. O tamanho das partículas foi determinado utilizando o software de tratamento de imagens ImageJ.

A reação de esterificação da celulose obtida dos talos de casca de banana foi feita a partir de uma adaptação do processo descrito por CERQUEIRA et al. [20] onde adicionou-se em $1 \mathrm{~g}$ de celulose liofilizada, $50 \mathrm{~mL}$ de ácido acético glacial e manteve-se essa solução sob agitação por 30 minutos. Após, adicionou-se a solução de celulose, uma mistura de $0,160 \mathrm{ml}$ de ácido sulfúrico com $18 \mathrm{~mL}$ de ácido acético glacial, mantendo-se essa solução por mais 30 minutos de agitação. Ao final, a solução foi então filtrada e adicionou-se $64 \mathrm{~mL}$ de anidrido acético ao filtrado, devolvendo-se a mistura a polpa de celulose. A mistura foi novamente agitada por 30 minutos e permaneceu em repouso por 14 horas. Transcorrido o repouso, a mistura foi filtrada para remover eventuais partículas de celulose não dissolvidas, e ao filtrado adicionou-se $0,078 \mathrm{~g}$ das partículas de prata, valor correspondente a 5\% da massa final prevista na reação. A mistura foi homogeneizada sob agitação e após gotejou-se água destilada para promover a precipitação do compósito de acetato de celulose com partículas de prata. O compósito foi filtrado e lavado sucessivas vezes para a remoção do ácido residual, e permaneceu em um dessecador para a total remoção da umidade.

Para a caracterização química utilizou-se a espectroscopia por Infravermelho com Transformada de Fourrier (FTIR). As análises foram realizadas em um equipamento da marca Bruker modelo Alpha P, com varredura entre $4000 \mathrm{~cm}^{-1}$ e $500 \mathrm{~cm}^{-1}$, tanto para a celulose quanto para o compósito.

As propriedades térmicas foram avaliadas por análise termogravimétrica (TGA) e por calorimetria exploratória diferencial (DSC). Para a primeira utilizou-se um equipamento da marca TA Instruments modelo Q600. Os ensaios foram realizados a partir da temperatura ambiente até $800^{\circ} \mathrm{C}$ com uma taxa de aquecimento de $10^{\circ} \mathrm{C} / \mathrm{min}$. e atmosfera de nitrogênio $(50 \mathrm{ml} / \mathrm{min})$.

Os termogramas de DSC da celulose e do compósito foram obtidos utilizando-se um equipamento da TA Instruments, modelo Q20. As amostras foram submetidas a um programa de aquecimento de $30^{\circ} \mathrm{C}$ até $390^{\circ} \mathrm{C}$, com uma taxa de aquecimento de $10^{\circ} \mathrm{C} / \mathrm{min}$ e atmosfera de nitrogênio $(50 \mathrm{ml} / \mathrm{min})$.

Para a caracterização mecânica e morfológica das amostras foram confeccionados filmes com o compósito, os quais foram obtidos a partir da solubilização do material obtido em clorofórmio. Após a solubilização, a solução foi colocada em uma placa de petri para a lenta evaporação do solvente e formação de um filme. Por fim, o filme foi cortado com o formato de corpos de prova tipo V conforme estabelece a norma ASTM D638 e ensaiado em uma máquina de ensaio universal da marca Instron, modelo E3000 (4 corpos de prova com velocidade de ensaio de $1 \mathrm{~mm} / \mathrm{min}$ ). A partir desse ensaio determinou-se o módulo elástico (inclinação da reta no regime elástico), a tenacidade (área abaixo da curva tensão/deformação), a deformação e a tensão máxima. A morfologia foi avaliada utilizando um microscópio eletrônico de varredura da mesma marca e modelo utilizado para as partículas de prata. Para análise, foram cortados discos de $6 \mathrm{~mm}$ do filme, sendo esses metalizados com ouro antes da análise. A intensidade do feixe foi de 12 quilovolts para a fibra de celulose e 15 quilovolts para os filmes.

As propriedades óticas do filme de acetato de celulose foram determinadas utilizando a espectroscopia de UV-Vis em um equipamento da Molecular Devices, modelo Spectra Max M3 de 350 a $750 \mathrm{~nm}$. 
Para a análise da atividade antibacteriana do filme de acetato de celulose com partículas de prata, foi realizado o teste de difusão em ágar, [21]. Foram utilizadas as cepas bacterianas S. aureus ATCC 25923 e E. coli O157:H7 NCTC 12900, pertencentes a bacterioteca do Laboratório de Microbiologia de Alimentos, do Departamento de Ciência e Tecnologia Agroindustrial da Universidade Federal de Pelotas. Preparou-se os inóculos de cada bactéria a ser testada em água peptonada $0,1 \%$, e mediu-se a densidade ótica (DO) à $600 \mathrm{~nm}$ em espectrofotômetro leitor de microplacas (SpectraMax 190, Molecular Devices®), devendo estar em valores próximos a 0,25 - o que equivale aproximadamente a $10^{8} \mathrm{UFC} \mathrm{mL}^{-1}$. As suspensões bacterianas foram semeadas em superfícies de placas de Petri contendo ágar Muller Hinton (MH) com o auxílio de um suabe. Posteriormente, foram dispostos sobre a superfície do ágar MH já semeado discos de $6 \mathrm{~mm}$ de diâmetro dos filmes a serem testados, sendo um filme de acetato de celulose com $5 \%$ de partículas de prata, e outro filme de acetato de celulose sem a adição de prata. Como controle do teste, foram utilizados discos do antimicrobiano ampicilina $10 \mu \mathrm{g}$. As placas foram incubadas em estufa à $37^{\circ} \mathrm{C}$ durante 24 horas.

\section{RESULTADOS E DISCUSSÃO}

A Figura 1 apresenta as caracterizações realizadas por FTIR da celulose (1A) e do compósito de acetato de celulose contendo $5 \%$ de partículas de prata.

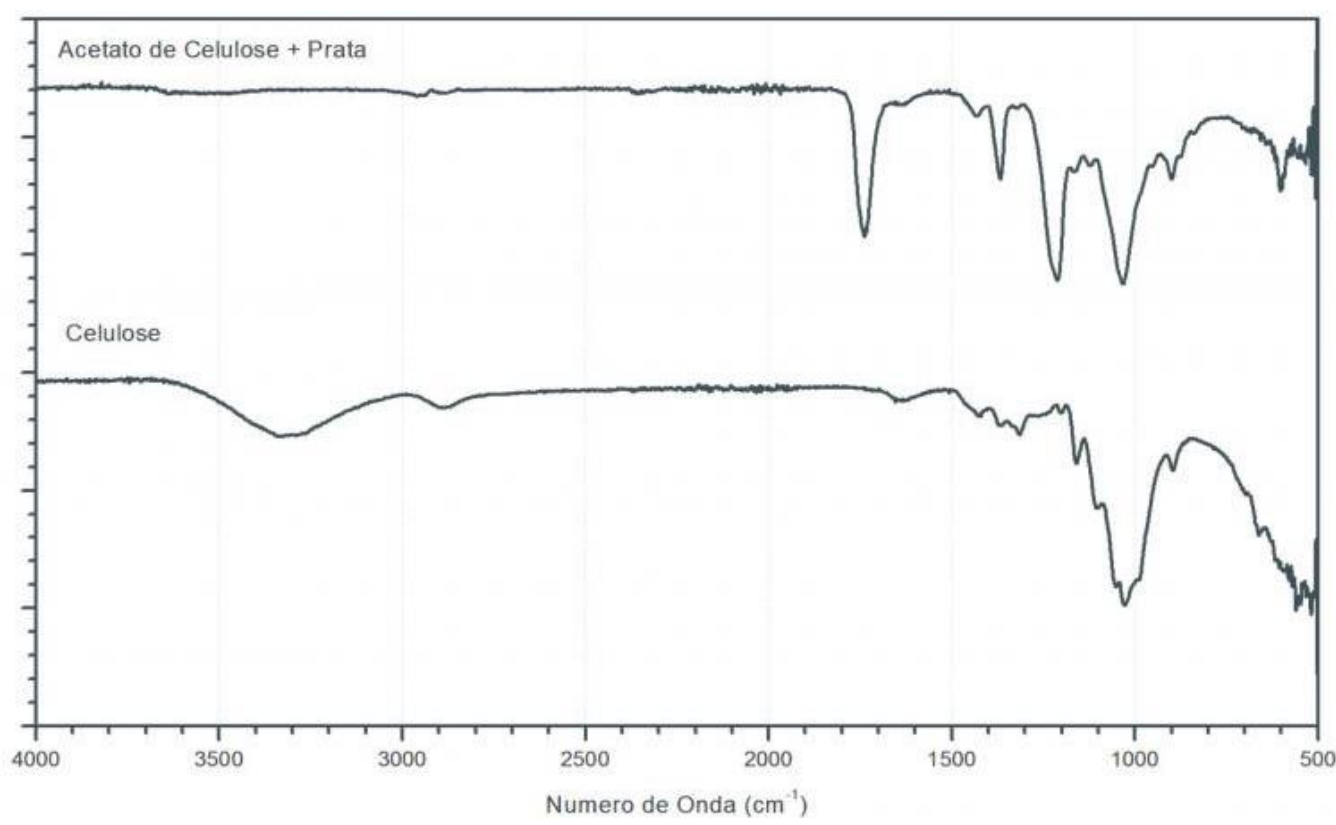

Figura 1: Espectrogrâmas no infravermelho da celulose e do compósito de acetato de celulose contendo 5\% de partículas de prata.

No espectro do infravermelho da celulose observa-se bandas em $890 \mathrm{~cm}^{-1}, 1060 \mathrm{~cm}^{-1}$ que correspon-

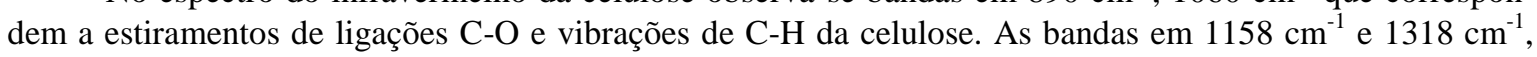
correspondem, respectivamente, a estiramentos assimétricos de ligações C-O-C da hemicelulose e/ou lignina. A banda em $1030 \mathrm{~cm}^{-1}$ é atribuída a ligações do tipo éter de lignina ou hemiceluloses [22].

A banda em 3300 - $3340 \mathrm{~cm}^{-1}$, corresponde as vibrações por estiramento de grupos hidroxilas presentes em ambas as amostras, que pode corresponder a adsorção de água, álcoois alifáticos primários e secundários presentes na celulose [23,24]. A banda em 2890-2900 $\mathrm{cm}^{-1}$ corresponde a as vibrações associadas a ligações CH [23]. Além disso, o fenômeno de absorção observado em $1212 \mathrm{~cm}^{-1}$ corresponde a ligações C-H, O$\mathrm{H}$ ou $\mathrm{CH}_{2}$. Vale ressaltar que as bandas em $1230 \mathrm{~cm}^{-1}, 1510 \mathrm{~cm}^{-1}, 1590 \mathrm{~cm}^{-1}$ e $1730 \mathrm{~cm}^{-1}$ características de grupos funcionais associados a lignina e a compostos de baixo peso molecular não estão presentes no espectro da celulose, indicando que o tratamento químico utilizado foi eficaz na remoção desses compostos, assim como descrito por IBRAHIM et al., NETO et al., SHELTAMI et al. e SILVÉVIO et al, [22-25].

Já no o espectro do compósito pode-se observar uma sensível redução na banda próxima a $3500 \mathrm{~cm}^{-1}$, indicando que os grupos hidroxilas da celulose foram substituídos por grupos acetilas. Tal fato é corroborado com o surgimento das bandas em $1740 \mathrm{~cm}^{-1}, 1366 \mathrm{~cm}^{-1}$ e $1211 \mathrm{~cm}^{-1}$ que, respectivamente, correspondem a estiramento simétrico da carbonila $(\mathrm{C}=\mathrm{O})$ presente no grupo acetila $[4,26]$, ligações do tipo $\mathrm{C}-\mathrm{H}$ do grupo 
acetila e ligações - $\mathrm{CO}$ - referentes a estiramento de bandas do grupo acetila [27].

Além das bandas já citadas destacam-se as regiões do espectro entre $600-700 \mathrm{~cm}^{-1}$, relativa a ligações -OH fora do plano [28]; Entre 1000-890 $\mathrm{cm}^{-1}$ que são característicos de ligações C-O dos grupos acetila [29]; Entre $1600 \mathrm{e} 1700 \mathrm{~cm}^{-1}$, referente a deformação angular da água [28] e por fim região entre 1500-1400 cm qual é correspondente a deformação assimétrica de $\mathrm{CH}_{3}$ [29].

Analisando-se os resultados de análise termogravimétrica (Figura 2), verifica-se que em $100^{\circ} \mathrm{C}$ ocorre um evento de perda de massa de $9 \%$ para a celulose e 5\% para o compósito, relativas a desidratação das amostras. $\mathrm{O}$ mais alto valor de perda de massa verificado na celulose se justifica pela maior afinidade dessa com a água [18,30,31], já o compósito, por ser hidrofóbico possui um menor teor de umidade residual, além do baixo teor de $-\mathrm{OH}[15]$.

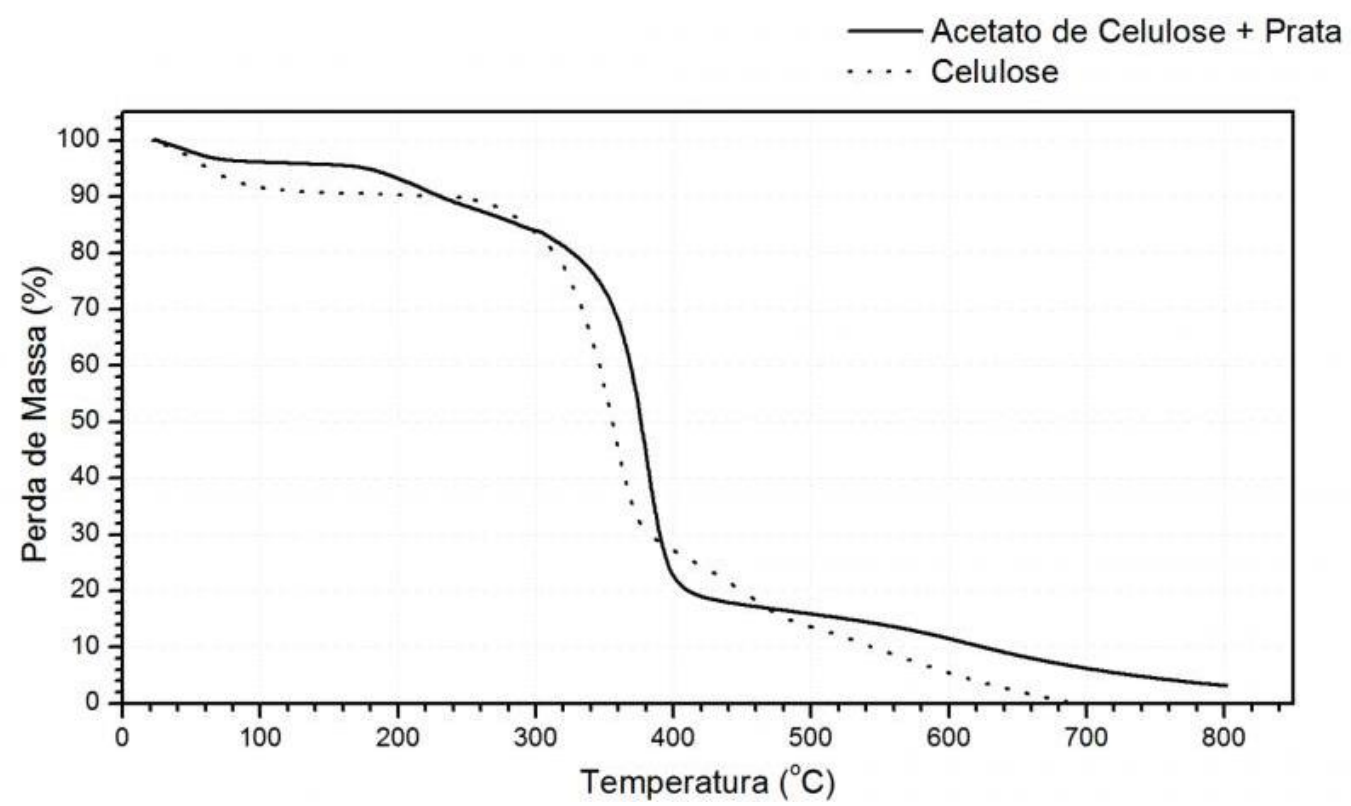

Figura 2: Termograma da celulose e do compósito de acetato de celulose contendo 5\% de partículas de prata.

Observa-se ainda na Figura 2 que a celulose sofre um segundo evento de perda de massa entre $230^{\circ} \mathrm{C}$ e $380^{\circ} \mathrm{C}$ que corresponde a degradação da hemicelulose e da celulose $\alpha$ presentes na amostra. A decomposição da hemicelulose inicia-se em $220^{\circ} \mathrm{C}$ e continua até os $300^{\circ} \mathrm{C}$, a celulose tem sua degradação iniciada perto dos $310^{\circ} \mathrm{C}$ até os $400^{\circ} \mathrm{C}$, enquanto a lignina apresenta temperaturas de degradação entre $200^{\circ} \mathrm{C}$ até $700^{\circ} \mathrm{C}$ [30]. Sacarídeos que compõe a hemicelulose e grupos glicosídicos da celulose são volatilizados, levando a formação de água e dióxido de carbono, alcanos e outros derivados de hidrocarbonetos [31]. Após $380^{\circ} \mathrm{C}$ o produto de degradação residual mantém um perfil lento de decomposição decorrente da carbonização dos produtos degradados na formação das cinzas $[18,32]$.

No compósito observa-se, além da desidratação inicial, perda de massa de $13 \%$ entre $170^{\circ} \mathrm{C}$ e $305^{\circ} \mathrm{C}$ decorrente da presença da hemicelulose na matéria-prima utilizada que reduz a sua estabilidade térmica, [26]. Entre $310^{\circ} \mathrm{C}$ e $420^{\circ} \mathrm{C}$ observa-se uma perda de massa de $64 \%$, decorrente da degradação das cadeias do acetato de celulose, ligninas residuais acetiladas e subprodutos da hemicelulose [32,33]. Após $420^{\circ} \mathrm{C}$ observa-se uma perda constante de massa decorrente da carbonização dos produtos degradados [32], contudo após os $700^{\circ} \mathrm{C}$, o compósito apresenta uma alta estabilidade térmica em função da adição das partículas de prata [15]. Vale ressaltar que após atingir-se a temperatura de $800^{\circ} \mathrm{C}$, a amostra permaneceu com aproximadamente $3 \%$ de massa, visto que as partículas de prata não sofrem degradação nas temperaturas utilizadas.

A Figura 3 apresenta os termogramas de DSC obtidos para a celulose e compósito acetato de celulose/partículas de prata. Nela pode-se observar um pico endotérmico em ambas as amostras, em $50^{\circ} \mathrm{C}-60^{\circ} \mathrm{C}$, relativo a desidratação e um segundo pico endotérmico na celulose em $348,25^{\circ} \mathrm{C}$ é relativo a degradação da hemicelulose e celulose [34]. A hemicelulose sofre degradação entre $240^{\circ} \mathrm{C}$ e $345^{\circ} \mathrm{C}$, ao passo que a celulose se decompõe entre $290^{\circ} \mathrm{C}$ e $375^{\circ} \mathrm{C}$. A diferença de temperaturas entre elas se deve aos diferentes constituintes de cada uma. A primeira por ser feita de sacarídeos como xilose, manose, glucose, galactose, etc, organizados em uma estrutura amorfa, é mais facilmente removida por decomposição, um processo endotérmico. Já a segunda, é feita de longas cadeias de glucose, organizadas em estruturas de longo ordenamento, o que leva a 
uma maior estabilidade térmica.

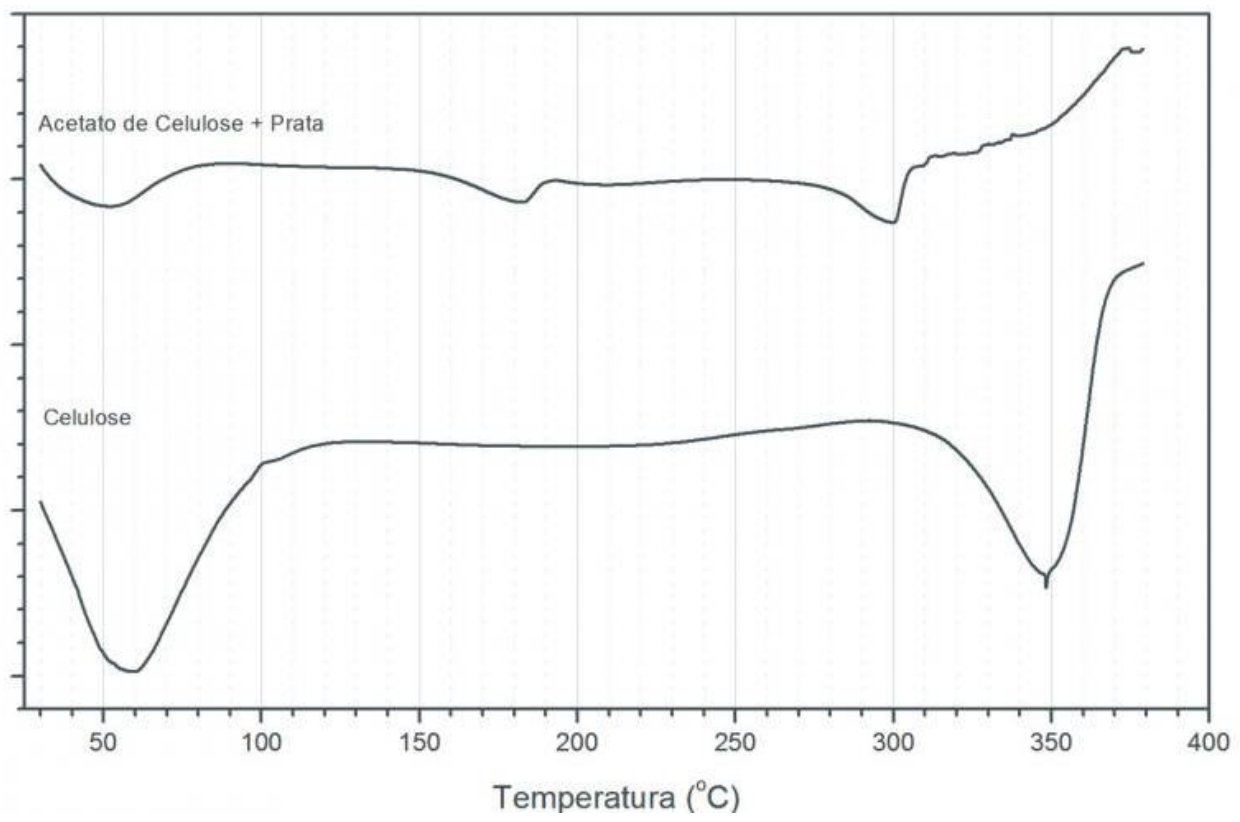

Figura 3: Termogramas de DSC da celulose e do compósito de acetato de celulose e 5\% de partículas de prata.

Analisando-se ainda o termograma obtido para o compósito, verifica-se que além da região relativa a desidratação em $50^{\circ} \mathrm{C}$, há uma mudança na linha de base em $180^{\circ} \mathrm{C}$ relativa a temperatura de transição vítrea do material $\left(\mathrm{T}_{\mathrm{g}}\right)$ [35] e um pico endotérmico em $300^{\circ} \mathrm{C}$ correspondente a temperatura de fusão $\left(\mathrm{T}_{\mathrm{m}}\right)$ do material [36,37]. Já o pico exotérmico em $372^{\circ} \mathrm{C}$ é correspondente a degradação das cadeias de acetato de celulose, ligninas acetiladas e derivados da hemicelulose [32,33].

A análise de UV-vis da Figura 4 apresenta um comparativo entre um filme com e outro sem a adição de partículas de prata, onde observa-se que o segundo apresentou menor absorbância, indicando ser mais translúcido. Tal resultado pode ser melhor observado na Figura 5, onde é possível notar a diferença de transparência entre os filmes.

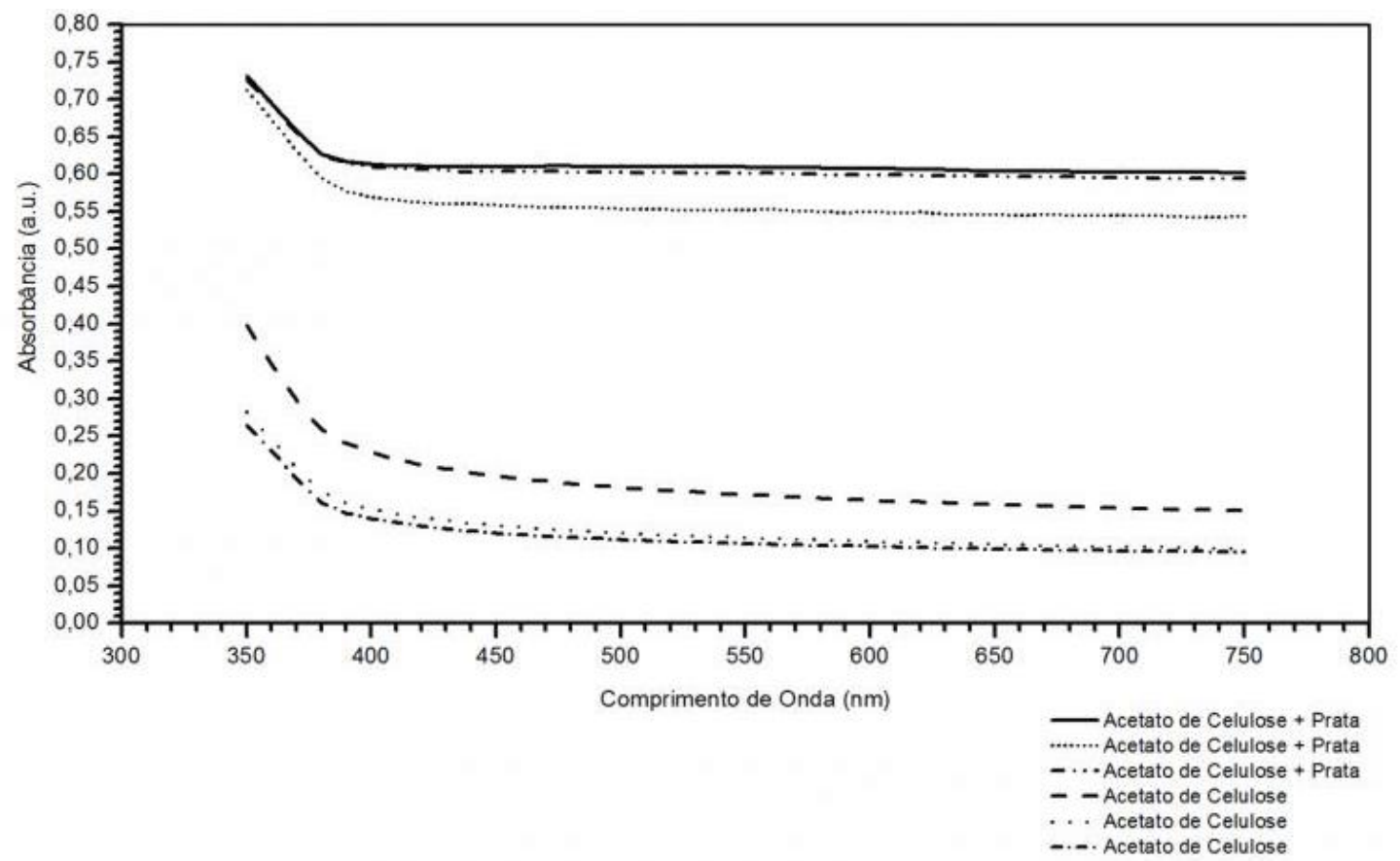

Figura 4: Resultados da espectroscopia no UV-visível para filmes de acetato de celulose com e sem partículas de prata. 


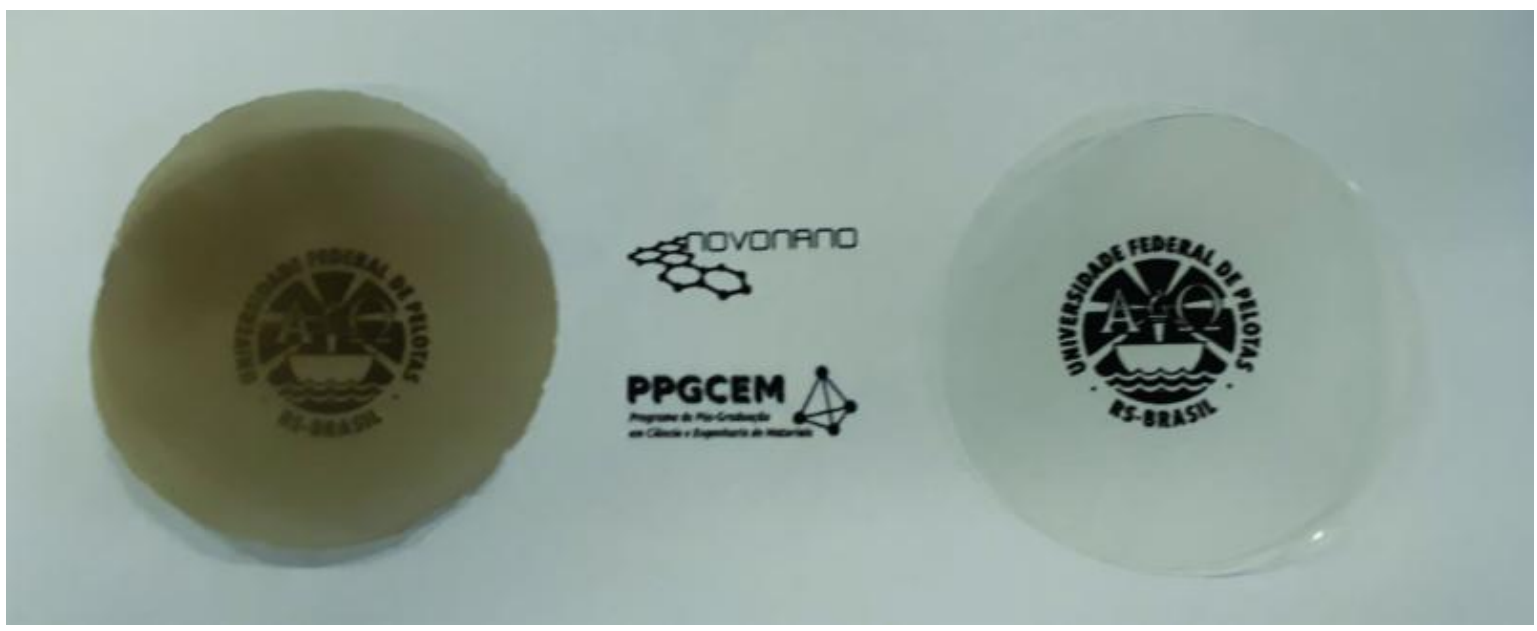

Figura 5: Filme de acetato de celulose contendo 5\% de partículas de prata (esquerda) e filme de acetato de celulose puro (direita).

A tabela 1 apresenta os resultados do ensaio mecânico para o compósito de acetato de celulose contendo 5\% em massa de partículas de prata. Os resultados obtidos para o módulo de elasticidade, tenacidade, deformação na ruptura e tensão na ruptura são apresentados abaixo.

Tabela 1: Resultados do ensaio mecânico do filme de acetato de celulose contendo 5\% de partículas de prata.

\begin{tabular}{ccccc}
\hline \multirow{2}{*}{ AMOSTRA } & $\begin{array}{c}\text { MODULO ELÁSTICO } \\
(\mathrm{MPa})\end{array}$ & $\begin{array}{c}\text { TENACIDADE } \\
\left(\mathrm{N} / \mathrm{mm}^{2}\right)\end{array}$ & $\begin{array}{c}\text { DEFORMAÇÃO MÁXIMA } \\
(\%)\end{array}$ & $\begin{array}{c}\text { TENSÃO MAXIMA } \\
(\mathrm{MPa})\end{array}$ \\
\hline 1 & 10,78 & 2,96 & 7,94 & 53,19 \\
\hline 3 & 11,61 & 1,87 & 5,94 & 46,07 \\
\hline 4 & 13,06 & 4,25 & 10,48 & 48,92 \\
\hline MÉDIA & 9,05 & 2,07 & 7,52 & 37,91 \\
\hline DESVIO & 11,12 & 2,79 & 7,97 & 46,52 \\
\hline
\end{tabular}

O acetato de celulose comercial (Sygma Aldrich) apresenta tensão de ruptura de 37,02 MPa $( \pm 2,33)$ [38] ao passo que o compósito desenvolvido nesse trabalho apresentou tensão média de 46,52 $\mathrm{MPa}( \pm 5,58) \mathrm{o}$ que representa um acréscimo de aproximadamente $25 \%$.

A Figura 6 apresenta as imagens obtidas por microscopia eletrônica de varredura da celulose (Figura 6A 100x, Figura 6B 1000x e Figura 6C 5000x) das partículas de prata (Figura 6D 1000x, Figura 6E 5000x e Figura 6F 10000x) e do compósito (Figura 6G 500x, Figura 6H 2000x e Figura 6I 5000x). 

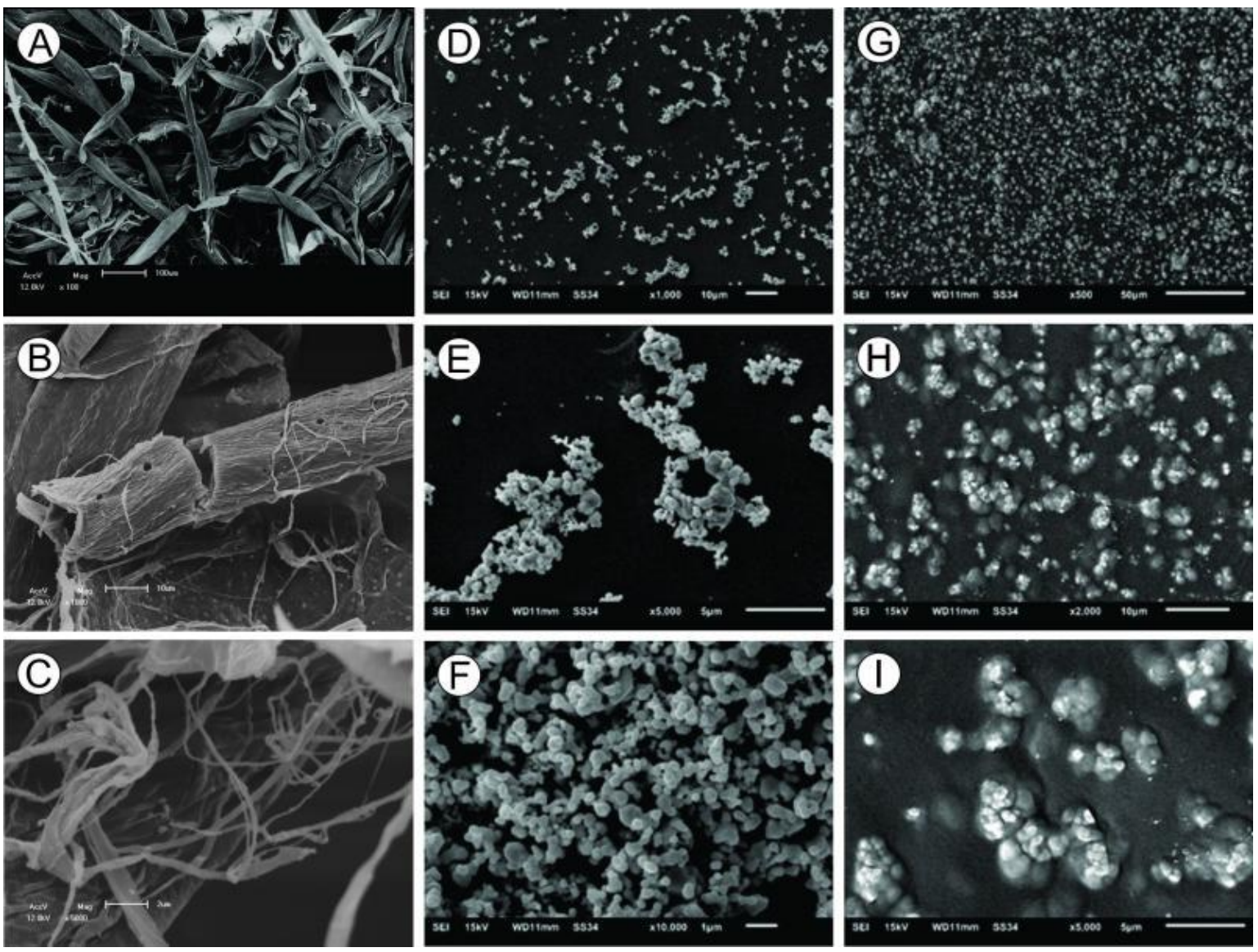

Figura 6: Imagens de microscopia eletrônica de varredura da celulose em aumentos de 100x (A), 1000x (B) e 5000x (C), das partículas de prata em aumentos de 1000x (D), 5000x (E) e 10000x (F) e do filme de acetato de celulose com partículas de prata em aumentos de 500x (G) 2000x (H) e 5000x (I).

Nas imagens obtidas para a celulose é possível observar que as fibras se apresentaram em forma de fitas, com largura média de 30,44 $\mu \mathrm{m}( \pm 4,04)$. Essa morfologia é resultado da ligação entre as fibrilas elementares formando as macrofibrilas [39]. Nas imagens em maior magnificação é possível observar as fibrilas que se desprenderam das macrofibrilas. Essas apresentaram um diâmetro médio de 212,83 nm $( \pm 62,39)$.

Nas imagens das partículas de prata (Figuras 6D, 6E e 6F) observa-se uma predominância de partículas com formato esférico, e um tamanho médio de partículas da ordem de $0,4336 \mu \mathrm{m}( \pm 0,1046)$, indicando que as partículas de prata não podem ser classificadas como nanométricas. É verificado também a formação de aglomerados com tamanhos e formatos variados. O resultado obtido após a síntese não foi o esperado, uma vez que a metodologia utilizada descreve a obtenção de nanopartículas de prata entre $24 \mathrm{~nm}$ e $132 \mathrm{~nm}$.

As micrografias do compósito (Figura 6G, 6H e 6I) revelaram que as partículas de prata se encontram aglomeradas na matriz de acetato de celulose, formando clusters de diversos tamanhos, sendo alguns constituídos por poucas unidades enquanto outros possuem dezenas de partículas de prata. Os aglomerados de prata encontram-se dispersos por toda a superfície do filme, sendo observadas poucas regiões sem a presença de nenhuma partícula metálica. Além disto, não se observou no filme a presença de porosidade, bolhas, fissuras ou outro defeito que possa comprometer o desempenho do material.

A Figura 7A apresenta placa de petri contendo ágar MH cultivadas com S. aureus incubadas por 24 horas com o disco controle (a-ampicilina) à direita e o disco de acetato de celulose sem as partículas de prata à esquerda. Na imagem 7B vemos a placa de petri contendo ágar MH cultivadas com S. aureus incubadas por 24 horas com o disco de acetato de celulose com as partículas de prata (placa da direita). Já a figura 7C apresenta placas de petri contendo ágar MH cultivadas com E. coli incubadas por 24 horas com os discos controle (a-ampicilina) à direita e de acetato de celulose sem partículas de prata à esquerda. A figura 7D vemos a placa de petri contendo ágar MH cultivadas com E. coli incubadas por 24 horas e o disco de acetato de celulose com partículas de prata. Nelas verificou-se que não ocorreram halos de inibição ao redor dos discos do filme de acetato de celulose com partículas de prata para ambas as bactérias testadas (Figura 7A dir. e 7B dir.), 
porém não houve crescimento bacteriano embaixo do disco, sugerindo que em contato direto com o filme contendo as partículas de prata há inibição do crescimento de S. aureus (Figura 7E) e E. coli (Figura 7F).
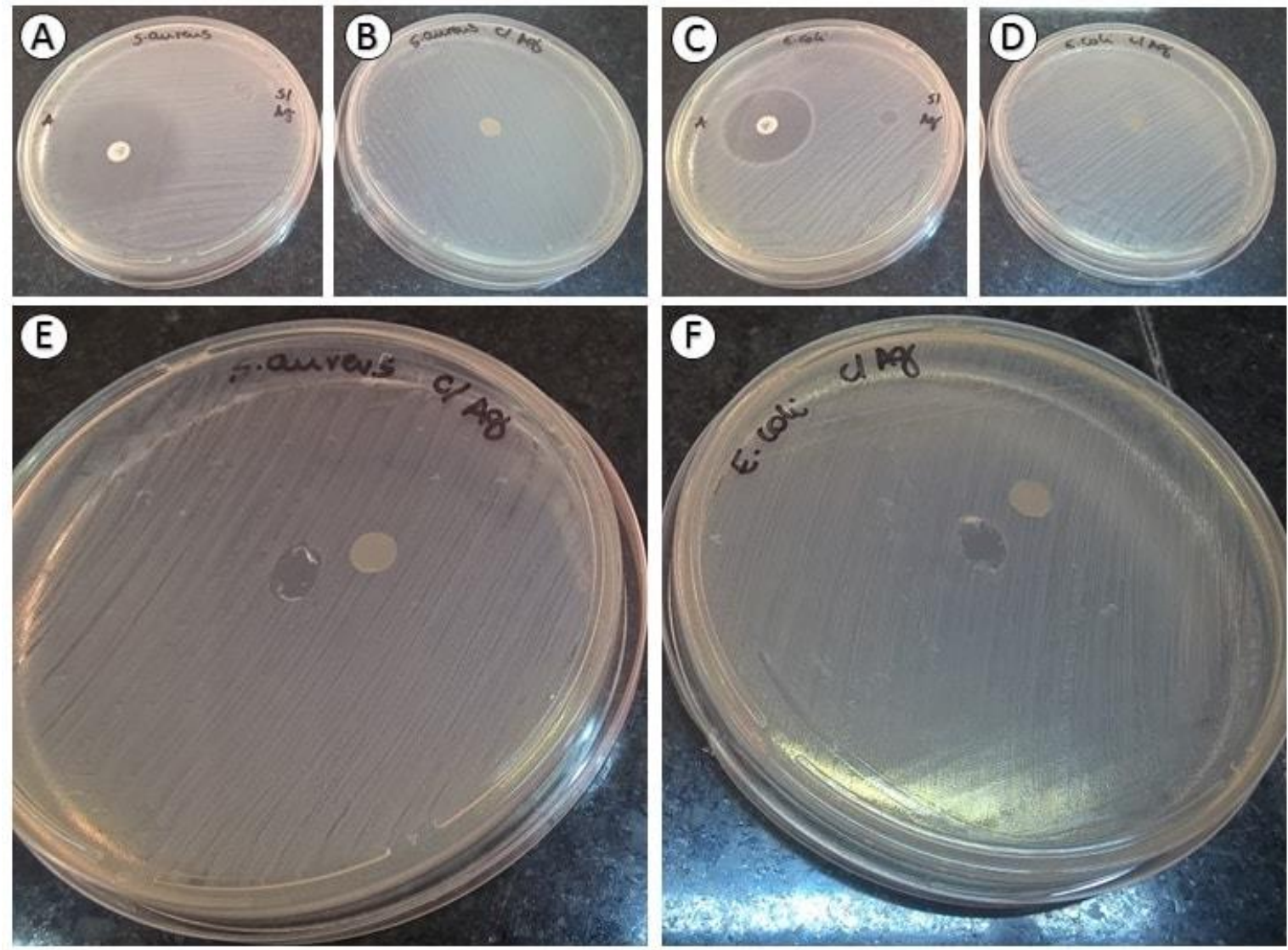

Figura 7: Placas de ágar MH após 24 horas de incubação - (A) Disco de a-ampicilina (esq.), de acetato de celulose (dir.) inoculada com S. aureus; (B) Disco de acetato de celulose com partículas de prata inoculada com S. aureus; (C) Disco de a-ampicilina e de acetato de celulose inoculada com E. coli; (D) Disco de acetato de celulose com partículas de prata inoculada com E. coli; Discos com partículas de prata deslocados - (E) S. aureus e (F) E. coli.

Resultados semelhantes foram encontrados na literatura, onde ao avaliar-se a atividade antibacteriana de membranas de fibras ocas de acetato de celulose contendo partículas de prata através do método de difusão em ágar, testando as mesmas espécies bacterianas [11].

O mecanismo de ação das partículas de prata sobre a célula bacteriana não está suficientemente elucidado, porém autores sugerem que as nanopartículas de prata danificam as células bacterianas enfraquecendo as membranas celulares e destruindo enzimas que transportam os nutrientes das células, causando a morte celular e, consequentemente, prolongando a vida útil dos alimentos [1].

Porém, como relatado anteriormente, as partículas de prata no filme de acetato de celulose desse estudo não ficaram em escala nanométrica, sendo provavelmente o fator responsável pela diminuição do espectro de ação contra as bactérias e pela apoptose bacteriana somente na área de contato com o filme. O tamanho das moléculas de polímero e sua pouca solubilidade na água impedem que os micro-organismos as transportem para o interior de suas células, onde a maioria dos processos bioquímicos ocorre, ou seja, as moléculas não penetram na membrana celular e não causam apoptose [40].

\section{CONCLUSÕES}

Os resultados obtidos nesse trabalho nos permitiram concluir que as fibras celulósicas extraídas de talos de casca de banana puderam ser utilizadas para a produção de acetato de celulose por meio de reação de esterificação utilizando anidrido acético como fornecedor de grupos acetila. Além disto, o polímero de acetato de celulose mostrou uma boa distribuição dos clusters de prata micrométricas obtidas por meio da síntese hidrotérmica assistida por micro-ondas. O compósito de acetato de celulose com partículas de prata, além da boa 
dispersão, não apresentou defeitos como bolhas, fissuras ou porosidade, o que contribuiu para o bom desempenho mecânico, apresentando tensão de ruptura cerca de $25 \%$ superior a polímeros comerciais sem a adição de cargas e menor transparência quando comparado a um polímero puro. A atividade antimicrobiana foi observada somente em contato direto da bactéria com o filme, não havendo a formação de halo de inibição.

\section{AGRADECIMENTOS}

Os autores agradem à CAPES, CNPQ, FINEP e FAPERGS por todo suporte financeiro para a realização desta pesquisa. Os autores agradecem também à UFPel, UFCG, FURG e CEME-Sul e demais colaboradores.

\section{BIBLIOGRAFIA}

[1] SILVESTRE, C., DURACCIO, D., CIMMINO, S. "Food packaging based on polymer nanomaterials", Progress in Polymer Science v. 36 pp. 1766-1782, 2011.

[2] SUKAN, A., ROY, I., KESHAVARZ, T. "Agro-Industrial Waste Materials as Substrates for the Production of Poly(3-Hydroxybutyric Acid)", Journal of Biomaterials and Nanobiotechnology, v. 5, pp. 229-240, 2014.

[3] REBOUILLAT, S., PLA, F. "State of the Art Manufacturing and Engineering of Nanocellulose: A Review of Available Data and Industrial Applications", Journal of Biomaterials and Nanobiotechnology, v. 4, pp. 165-188, 2013.

[4] ALIM BAHMID, N., SYAMSU, K., MADDU, A., "Production of Cellulose Acetate from Oil Palm Empty Fruit Bunches", Chemical and Process Engineering Research, v. 17, pp. 12-20, 2013.

[5] KONTOMINAS, M., Bioactive Food Packaging: Strategies, Quality, Safety, Lancaster, Pennsylvania, Ed. DEStech Publications, 2016.

[6] BRASIL, Doenças Transmitidas por Alimentos 2015, http://portalarquivos.saude.gov.br. Acessado em fevereiro de 2017.

[7] FORSYTHE, S. J. Microbiologia da Segurança Alimentar, Porto Alegre, Ed. Artmed, 2002.

[8] BRUNA, J. E., GALOTTO, M. J., GUARDA, A., et al., "A novel polymer based on $\mathrm{MtCu} 2+$ / cellulose acetate with antimicrobial activity", Carbohydrate Polymers, v. 102, pp. 317-323, 2014.

[9] QUIRÓS, J., GONZALO, S., JALVO, B., et al., "Science of the Total Environment Electrospun cellulose acetate composites containing supported metal nanoparticles for antifungal membranes", Science of the Total Environment., v. 653-564, pp. 912-920, 2016.

[10] HYUK, K., JOON, Y., HA, Y., et al., "Antimicrobial activity of cellulose-based nano fi bers with different Ag phases", Materials. Letters. v. 116, pp. 146-149, 2014

[11] CHOU, W.-L., YU, D.-G., YANG, M.-C. "The preparation and characterization of silver-loading cellulose acetate hollow fiber membrane for water treatment", Polymers For Advanced Technologies , v, 16, pp. 600-607, 2005.

[12] SON, W. K., YOUK, J. H., PARK, W. H. "Antimicrobial cellulose acetate nanofibers containing silver nanoparticles”, Carbohydrate Polymers, v. 65, pp. 430-434, 2006.

[13] TIAN, X., LI, Y., WAN, S., et al., "Functional Surface Coating on Cellulosic Flexible Substrates with Improved Water-Resistant and Antimicrobial Properties by Use of ZnO Nanoparticles", Journal of Nanomaterials, 2017.

[14] GOPIRAMAN, M., WAHAB, A., HIROMICHI, S., et al., "Silver coated anionic cellulose nanofiber composites for an efficient antimicrobial activity", Carbohydrate Polymer, v. 149, pp. 51-59, 2016.

[15] VARSHA, C., BAJPAI, S. K., NAVIN, C. "Investigation of water vapour permeation and antibacterial properties of nano silver loaded cellulose acetate film", International Food Research Journal, v. 17, pp. 623$639,2010$.

[16] BELTRAN, J. E., PANIZ, O. G., GONÇALVES, M. R. F., "Metodologia De Extraçâo De Fibras De Talos De Cascas De Banana", In: XV Encontro de Pós Graduação da Universidade Federal de Pelotas. Pelotas, Rio Grande do Sul - Brasil 2013.

[17] PANIZ, O. G., BELTRAN, J. E., GONÇALVES, R. F., "Obtenção E Caracterização De Fibras De Talos De Cascas De Banana", In: .Anais XXII Congresso de Iniciação Científica da UNiversidade Federal de Pelotas. Pelotas, Rio Grande do Sul - Brasil 2013. 
[18] ELANTHIKKAL, S., GOPALAKRISHNAPANICKER, U., VARGHESE, S., et al., "Cellulose microfibres produced from banana plant wastes: Isolation and characterization", Carbohydrate Polymers, v. 80, pp. 852-859, 2010.

[19] YIN, H., YAMAMOTO, T., WADA, Y., et al., "Large-scale and size-controlled synthesis of silver nanoparticles under microwave irradiation", Materials Chemistry and Physics, v. 83, pp. 66-70, 2004.

[20] CERQUEIRA, D. A., FILHO, G. R., CARVALHO, R. A., et al., "Caracterização de acetato de celulose obtido a partir do bagaço de cana-de-açúcar por 1H- RMN", Polímeros, v. 20, n. 2, pp. 85-91, 2010.

[21] BAUER, A., KIRBY, W., SHERRIS, J., et al., "Antibiotic susceptibility testing by a standardized single disc method", The American Journal of Clinical Patholpgy, v. 45, n. 4, pp. 493-496, 1966.

[22] SILVÉRIO, H. A., FLAUZINO NETO, W. P., DANTAS, N. O., et al., "Extraction and characterization of cellulose nanocrystals from corncob for application as reinforcing agent in nanocomposites", Industrial Crops and Products, v. 44, pp. 427-436., 2013.

[23] IBRAHIM, M. M., DUFRESNE, A., EL-ZAWAWY, W. K., et al., "Banana fibers and microfibrils as lignocellulosic reinforcements in polymer composites", Carbohydrate Polymers, v. 81, pp. 811-819, 2010.

[24] SHELTAMI, R. M., ABDULLAH, I., AHMAD, I., et al., "Extraction of cellulose nanocrystals from mengkuang leaves (Pandanus tectorius)", Carbohydrate Polymers, v. 88, pp. 772-779, 2012.

[25] NETO, W. P. F., SILVÉRIO, H. A., DANTAS, N. O., et al., "Extraction and characterization of cellulose nanocrystals from agro-industrial residue - Soy hulls", Industrial Crops and Products, v. 42, pp. 480488, 2013.

[26] LOO, M. M. L., HASHIM, R., LEH, C. P., "Recycling of valueless paper dust to a low grade cellulose acetate: Effect of pretreatments on acetylation”, BioResources, v. 7, n. 1, pp. 1068-1083, 2012.

[27] CAO, J., SUN, X., LU, C., et al., "Water-soluble cellulose acetate from waste cotton fabrics and the aqueous processing of all-cellulose composites", Carbohydrate Polymers, v. 149, pp. 60-67, 2016.

[28] FAN, M., DAI, D., HUANG, B. "Fourier Transform Infrared Spectroscopy for Natural Fibres", Fourier Transform - Materiials. Analysis, pp. 45-68, 2012.

[29] MARK, J. E. "Polymer Data Handbook”, Ed. Oxford Univesity Press, New York, v. 1, 2009.

[30] ABRAHAM, E., DEEPA, B., POTHAN, L. A., et al., "Extraction of nanocellulose fibrils from lignocellulosic fibres: A novel approach", Carbohydrate Polymers, v. 86, pp. 1468-1475, 2011.

[31] PELISSARI, F. M., SOBRAL, P. J. D. A., MENEGALLI, F. C., "Isolation and characterization of cellulose nanofibers from banana peels", Cellulose, v. 21, pp. 417-432, 2014.

[32] RODRÍGUEZ, F. J., GALOTTO, M. J., GUARDA, A., et al., "Modification of cellulose acetate films using nanofillers based on organoclays", Journal of Food Engineering, v. 110, pp. 262-268, 2012.

[33] RODRIGUES FILHO, G., MONTEIRO, D. S., MEIRELES, C. DA S., et al., "Synthesis and characterization of cellulose acetate produced from recycled newspaper", Carbohydrate Polymers, v. 73, pp. 74-82, 2008.

[34] FRANCO, F. J. P. Aproveitamento Da Fibra Do Epicarpo Do Coco Babaçu Em Compósito Com Matriz De Epóxi : Estudo Do Efeito Do Tratamento Da Fibra, Dissertação M.Sc., PPGCEm/UFRN, Natal, RN, Brasil 2010.

[35] TANG, C., CHEN, P., LIU, H., "Cocontinuous cellulose acetate/polyurethane composite nanofiber fabricated through electrospinning", Polymer Engineering And Science, v. 48, pp. 1296-1303, 2008.

[36] CERQUEIRA, D. A., RODRIGUES FILHO, G., ASSUNÇÃO, R. M. N. "A new value for the heat of fusion of a perfect crystal of cellulose acetate", Polymer Bulletin, v. 56, pp. 475-484, 2006.

[37] KAMIDE, K., SAITO, M. "Thermal analysis of cellulose acetate solids with total degrees of substitution of 0.49, 1.75, 2.46, and 2.92", Polymer Journal, v. 17, pp. 919-928, 1985.

[38] WITTHAYAPRAPAKORN, C., THANANUKUL, K.., et al., "Preparation of Biodegradable Polymer Blended of Poly(L-Lactic Acid)/Cellulose Acetate Films in the Solvent Mixture", Advanced Materials Research, v. 664, pp. 702-706, 2013.

[39] DING, S. Y., ZHAO, S., ZENG, Y., "Size, shape, and arrangement of native cellulose fibrils in maize cell walls", Cellulose, v. 21, pp. 863-871, 2014.

[40] ARTHAM, T., DOBLE, M., "Biodegradation of aliphatic and aromatic polycarbonates", Macromoleculas Bioscience, v. 8, pp. 14-24, 2008. 